\title{
The Norwegian Polio Study 1994 part II: early experiences of polio and later psychosocial well-being
}

\author{
A-K Schanke*,1, B Lobben ${ }^{2}$ and S Øyhaugen ${ }^{3}$ \\ ${ }^{1}$ Sunnaas Rehabilitation Hospital, 1450 Nesoddtangen, Norway; ${ }^{2}$ Sundgt. 8, 3300 Hokksund, Norway; ${ }^{3}$ Edv. \\ Munchsgt. 41, 3155 Åsgårdstrand, Norway
}

\begin{abstract}
Study design: The Norwegian Polio Study 1994 was a nation-wide survey of the medical and psychosocial situation of polio survivors.

Method: A questionnaire, consisting of 133 questions with sub-questions, was sent to a total of 2392 polio victims, most of them registered in 'The National Society of Polio Victims' in Norway. 1449 (61\%) answered.

Objectives: To investigate the relationship between early polio experiences, such as duration of hospitalization and perceived support, and later psychosocial well-being.

Results: Three hundred and ninety-one persons $(27 \%)$ reported they had been psychologically harmed by the treatment received at the time they contracted polio (Harmed group), while 1053 persons $(73 \%$ ) did not (Non-Harmed group). Persons in the Harmed group were significantly younger at polio onset, were hospitalized for a longer period and had less parental visit and support. Today they use more medication, report more pain, general fatigue, sleep disturbance and concentration problems, more psychosocial distress, less satisfaction with life and less social support than persons in the Non-Harmed group.

Conclusions: The results demonstrate that a subgroup of polio survivors has been vulnerable from childhood, with possible consequences for their physical, psychological and social wellbeing later in life. Recommendations for long-life treatment of children with similar diseases should include follow-up not only of their physical disabilities, but also on psychological and psychosocial needs.
\end{abstract}

Keywords: poliomyelitis; post polio syndrome; psychosocial well-being; rehabilitation

\section{Introduction}

The clinical features of the late effects of poliomyelitis, or post-polio syndrome, have been recognized since the mid 1980's. ${ }^{1-3}$ New interest in the situation of polio survivors has also led to research on psychological, emotional and behavioural aspects. Two studies presented a 5-year follow-up on the psychosocial adaptation to the late effects of polio, ${ }^{4,5}$ but the impact of early treatment on later psychological wellbeing has hitherto not been studied. Thus, the aim of the present study was to examine differences in psychological well-being as a function of early treatment of poliomyelitis.

During the epidemics in the 40's and 50's, harsh treatment was given to children with acute poliomyelitis. In many hospitals and institutions rigorous routines were strictly followed, emotional support was limited, and parental visits and care were restricted or prohibited. ${ }^{6-9}$ Robinson et al. were struck by the childrens' submissiveness, ${ }^{10}$ explained by Davis ${ }^{9}$ and Robinson et al. ${ }^{10}$ as a reaction to the

*Correspondence: A-K Schanke, Sunnaas Rehabilitation Hospital, 1450 Nesoddtangen, Norway feeling of guilt. Schafer described "pollyannish orientation' i.e. to be conscious of only cheerful and optimistic aspects of experience. ${ }^{11}$ In a 3-year followup of children with acute poliomyelitis, Meyer concluded that poliomyelitis 'tends to produce interference with normal mental and emotional development'. ${ }^{12}$ Another study of 100 children followed after acute poliomyelitis concluded that $38 \%$ of the children had serious enough psychological problems for their parents to be worried. ${ }^{13}$

Psychological studies on the late effects of polio have yielded inconsistent results. Type A behaviour, in terms of being competent, hard-driving and timeconscious over-achievers, was found to be significantly higher in polio survivors compared to control groups in some studies, ${ }^{14,15}$ but other studies have been inconclusive. ${ }^{16}$ Andersson and Hofft found no evidence of psychophysiological arousal or type A behaviour. ${ }^{17}$ Bruno and Frick found that type A scores were high in subjects who agreed with a statement that emotional stress initiates or exacerbates their physical symptoms, and also in subjects who experienced symptoms such as anxiety, headache, 
sleep problems, muscle pain and fatigue. ${ }^{14}$ Three studies have found elevated depression scores and psychological distress among polio survivors, ${ }^{18-20}$ while two studies did not. ${ }^{21,22}$ Tate et al. found that those subjects who demonstrated depression reported increased pain, decreased health status, decreased satisfaction with life and work, and poorer coping behaviours. ${ }^{22}$ In a study by Kuehn and Winters a significant negative correlation was found between coping resources and both quantity and severity of symptomatic distress, respectively. ${ }^{23}$ Kemp et al. concluded in their study that post polio status by itself did not relate to higher depression score or lower life satisfaction, while family functioning and attitude towards disability were more important. ${ }^{24}$ Grafman, reviewing polio studies, stated that 'no relationship is apparent between the report of psychopathological symptoms and degree of physical disability'. ${ }^{25}$ In the present study we wanted to focus upon a possible relationship between early treatment and later psychological well-being. We state the hypothesis that those reporting that they were harmed by the early treatment, were hospitalized longer and remember getting less comfort and support.

\section{Methods}

The study is based upon the Norwegian Polio Study 1994, which was done by 'The National Society for Polio Survivors' (LFPS) in collaboration with several professionals. ${ }^{26}$ The questionnaire consisted of 133 questions covering respondents' medical problems, earlier treatment for polio and current treatment for post polio symptoms, social situation, psychological well-being and future needs for health services. The questions were based upon those asked in national surveys from USA, France and Denmark, except that more questions covered the early history of polio. ${ }^{27-29}$

The questionnaire was sent to a total of 2392 polio survivors, 1288 women and 1104 men. Of those 2064 $(86 \%)$ were members of the LFPS. The remaining 398 were other polio survivors occasionally known. In total 1449 persons answered $(61 \%), 980$ women $(76 \%)$ and 459 men $(42 \%)$. Fourteen answers were excluded because of insufficient information. No reminder was sent. Demographic data, the level of paralysis in different phases of illness, the need for personal help, technical aids and need for current health services have previously been published. ${ }^{30}$ In an attempt to analyse the representativeness of the study group in relation to survivors of acute poliomyelitis, the number of responders were compared by Lande Wekre et al. with the number of acute polio cases notified to the medical health authorities each year from 1925 to $1964 .^{30}$ The comparison revealed that the responders represented about one tenth of the notified cases, with equal distribution of representation throughout the whole period. The response rate was slightly lower in the Northern part of Norway.

The Norwegian Polio Study 1994 include the following statement: 'I think I have been psychologi- cally harmed by the treatment received at the time I contracted polio'. The respondents' were divided into two groups, those reported being psychologically harmed by the early treatment (Harmed group) and those who did not (Not-Harmed group). The present analysis focuses on the psychosocial variables included in the questionnaire, combining data from the onset of polio with current psychosocial and health-related variables.

\section{Statistics}

The data were adjusted to the Norwegian sex distribution and population in different counties with a population of 1444, mainly by Feedback Research AS Oslo. This means that the proportion of men are adjusted to equal the population of polio survivors. Data were further analyzed using SPSS for Windows (release 6.0). Chi-square, ANOVA, and $t$-tests for independent samples were performed. Chosen levels of significance were $P<.01$ or $P<.001$. A stepwise multiple linear regression analysis was also performed in order to study the differences between the Harmed and the Non-Harmed group.

\section{Results}

In total 391 persons $(27 \%)$ answered 'yes' to the statement 'I think I have been psychologically harmed by the treatment received at the time I contracted polio' (Harmed or H-group). The rest, 1053 persons $(73 \%)$, answered either 'no', 'do not know' or 'irrelevant' (Non-Harmed group or NH-group).

Table 1 Demographic characteristics of subjects. Values for age are given in mean years $( \pm S D)$, the other values are given as percentage of the population

\begin{tabular}{|c|c|c|c|}
\hline Variable & $\begin{array}{l}\text { Harmed } \\
\text { group } \\
(\mathrm{n}=391)\end{array}$ & $\begin{array}{c}\text { Non-harmed } \\
\text { group } \\
(\mathrm{n}=1053)\end{array}$ & $\begin{array}{c}\text { Chi- } \\
\text { square/ } \\
\text { t-test }\end{array}$ \\
\hline \multicolumn{4}{|l|}{ Sex: } \\
\hline male & $47 \%$ & $46 \%$ & \\
\hline female & $53 \%$ & $54 \%$ & n.s. \\
\hline Age (mean, SD) & 55 years $( \pm 10) 58$ & 8 years $( \pm 10)$ & $P<0.001$ \\
\hline \multicolumn{4}{|l|}{ Marital status: } \\
\hline married/cohabitant & $66 \%$ & $73 \%$ & \\
\hline single & $34 \%$ & $27 \%$ & $P<0.01$ \\
\hline \multicolumn{4}{|l|}{ Education: } \\
\hline $1-9$ years & $65 \%$ & $64 \%$ & \\
\hline $10-12$ years & $29 \%$ & $31 \%$ & \\
\hline$>12$ years & $5 \%$ & $5 \%$ & n.s. \\
\hline \multicolumn{4}{|l|}{ Employment: } \\
\hline full-time & $18 \%$ & $27 \%$ & \\
\hline part-time & $17 \%$ & $13 \%$ & \\
\hline not working & $47 \%$ & $39 \%$ & \\
\hline old age pension & $18 \%$ & $20 \%$ & $P<0.001$ \\
\hline
\end{tabular}

n.s. $=$ no significant difference 
Demographics (Table 1)

There were no significant sex differences between the groups $(P>0.01)$. A higher percentage in the $\mathrm{NH}$ group were married. The H-group had a lower employment rate than the NH-group (Table 1).

\section{Onset of polio (Table 2)}

The mean age of members of the H-group were significantly younger than those in the NH-group when they contracted polio. However, median (6 versus 7 years), modus (2 versus 2 years) and range $(0-52$ years $)$ for both groups were mostly similar. In the acute phase, more members of the H-group than the NH-group had their lower extremities, back, neck and abdomen affected by polio. Duration of hospitalization was slightly, but significantly longer for the Hgroup. During the rehabilitation phase a higher percentage of the H-group was hospitalized, and their duration of hospitalization was significantly longer. Significantly more members in the H-group reported that they seldom or never were visited by relatives compared to the NH-group, and significantly more underwent orthopaedic surgery. Also significantly more members in the H-group stated that their parents did not give them enough care and support after they contracted polio.

\section{Current physical characteristics (Table 3)}

No differences in current body parts affected by polio or reported new weakness in polio-affected muscles were found between the groups, but a larger proportion of the H-group used mobility devices. The H-group reported significantly more often new health problems and use of medication.

Current psychosocial distress and life satisfaction (Table 4)

Members of the H-group were overrepresented on all measures on current psychological distress. Twenty-five per cent had received psychological treatment during the last 5 years compared to $5 \%$ in the NH-group. Further, $46 \%$ of the H-group reported need of treatment in the future, $15 \%$ in the NH-group.

Current general social support and current polio-related support (Table 5)

A significantly higher percentage of the H-group sometimes or often felt lonely. They also reported less understanding from their spouses and children than the NH-group.

Stepwise multiple linear regression analysis (Table 6)

Demographic characteristics (age, sex, marital status, occupational status and education) were entered in a stepwise procedure in step 1. Data about the onset of polio (body parts affected by polio, age at onset, hospitalization, duration of hospitalization, distance of hospital from home, frequency of visits, orthopaedic operations, support from parents) were entered in the same stepwise manner in step 2. Current physical

Table 2 Data from early onset of polio. Values given in mean $( \pm S D)$ or as percentage of the population

\begin{tabular}{|c|c|c|c|}
\hline Variable & $\begin{array}{l}\text { Harmed group } \\
\qquad(\mathrm{n}=391)\end{array}$ & $\begin{array}{l}\text { Non-harmed group } \\
\quad(\mathrm{n}=1053)\end{array}$ & $\begin{array}{l}\text { Chi-squarel } \\
\text { t-test }\end{array}$ \\
\hline Age at onset of polio (mean, SD) & 8 years $( \pm 17)$ & 10 years $( \pm 9)$ & $P<0.001$ \\
\hline \multicolumn{4}{|c|}{ Body parts affected by polio: (some/moderate/complete paresis): } \\
\hline upper extremities & $58 \%$ & $57 \%$ & n.s. \\
\hline lower extremities & $93 \%$ & $88 \%$ & $P<0.01$ \\
\hline both upper and lower extremities & $55 \%$ & $51 \%$ & n.s. \\
\hline back, neck, abdomen & $71 \%$ & $64 \%$ & $P<0.01$ \\
\hline respiratory muscles & $21 \%$ & $23 \%$ & n.s. \\
\hline swallow muscles & $12 \%$ & $9 \%$ & n.s. \\
\hline use of ventilator & $7 \%$ & $7 \%$ & n.s. \\
\hline \multicolumn{4}{|l|}{ Acute phase: } \\
\hline hospitalized & $74 \%$ & $70 \%$ & n.s. \\
\hline duration (mean, SD) & 6 months $( \pm 12)$ & 5 months $( \pm 7)$ & $P<0.001$ \\
\hline \multicolumn{4}{|l|}{ Rehabilitation phase: } \\
\hline hospitalized & $49 \%$ & $40 \%$ & $P<0.01$ \\
\hline duration (mead, SD) & 8 months $( \pm 18)$ & 5 months $( \pm 12)$ & $P<0.001$ \\
\hline $\begin{array}{l}\text { Visit by family during acute and rehabilitation phase: } \\
\text { seldom or never }\end{array}$ & $60 \%$ & $48 \%$ & $P<0.001$ \\
\hline Underwent surgery & $55 \%$ & $44 \%$ & $P<0.001$ \\
\hline $\begin{array}{l}\text { 'My parents did not give me care and support } \\
\text { when I contracted polio and grew up' }\end{array}$ & $12 \%$ & $5 \%$ & $P<0.001$ \\
\hline
\end{tabular}

n.s. $=$ no significant difference 
Table 3 Current physical characteristics and health-related symptoms. Values are given as percentage of the population

\begin{tabular}{|c|c|c|c|}
\hline Variable & $\begin{array}{l}\text { Harmed group } \\
(\mathrm{n}=391) \%\end{array}$ & $\begin{array}{l}\text { Non-harmed group } \\
\quad(\mathrm{n}=1053) \%\end{array}$ & $\begin{array}{c}\text { Chi-squarel } \\
\text { t-test }\end{array}$ \\
\hline \multicolumn{4}{|c|}{ Body parts affected by polio (some/moderate/complete paresis): } \\
\hline upper extremities & 45 & 41 & n.s. \\
\hline lower extremities & 80 & 74 & n.s. \\
\hline both upper and lower extremities & 83 & 82 & n.s. \\
\hline back and abdomen & 53 & 47 & n.s. \\
\hline respiratory muscles & 19 & 16 & n.s. \\
\hline swallow muscles & 7 & 5 & n.s. \\
\hline \multicolumn{4}{|c|}{ Use of mobility devices regularly or sometimes: } \\
\hline gr. 1: none & 38 & 48 & \\
\hline gr. 2: crutches/canes/orthoses & 37 & 31 & \\
\hline gr. 3: wheelchair & 25 & 21 & $P<0.01$ \\
\hline Use or respirator: & 6 & 3 & n.s. \\
\hline \multicolumn{4}{|l|}{ New weaknesses: } \\
\hline polio-affected muscles & 58 & 50 & n.s. \\
\hline non-affected muscles & 36 & 25 & $P<0.001$ \\
\hline \multicolumn{4}{|l|}{ New health problems: } \\
\hline pain in general & 72 & 52 & $P<0.001$ \\
\hline fatigue in general & 33 & 21 & $P<0.001$ \\
\hline concentration problems & 54 & 33 & $P<0.001$ \\
\hline sleep disturbances & 63 & 43 & $P<0.001$ \\
\hline Nightmares & 22 & 7 & $P<0.001$ \\
\hline \multicolumn{4}{|l|}{ Medication regularly or sometimes: } \\
\hline analgesics & 60 & 51 & $P<0.01$ \\
\hline sedatives & 32 & 16 & $P<0.001$ \\
\hline Other diseases & 48 & 40 & n.s. \\
\hline
\end{tabular}

n.s. $=$ no significant difference

Table 4 Current psychological distress and satisfaction. Values are given in percentage of the population

\begin{tabular}{|c|c|c|c|}
\hline Variable & $\begin{array}{l}\text { Harmed group } \\
(\mathrm{n}=391) \%\end{array}$ & $\begin{array}{l}\text { Non-harmed group } \\
\quad(\mathrm{n}=1053) \%\end{array}$ & $\begin{array}{l}\text { Chi-square/ } \\
\text { t-test }\end{array}$ \\
\hline \multicolumn{4}{|l|}{$\begin{array}{l}\text { Current psychological well-being (True to a great extent or to a } \\
\text { certain extent): }\end{array}$} \\
\hline 'Getting second disabilities was a psychological distress to me' & 90 & 67 & $P<0.001$ \\
\hline 'Today I feel that I cope well with the late effects of polio' & 71 & 82 & $P<0.001$ \\
\hline 'Today I suffer from anxiety, tension and worry' & 76 & 36 & $P<0.001$ \\
\hline 'Today I suffer from depression and dispiritedness' & 70 & 31 & $P<0.001$ \\
\hline 'I have received psychological treatment during the last 5 years' & 25 & 5 & $P<0.001$ \\
\hline \multicolumn{4}{|l|}{ Current satisfaction with life: } \\
\hline very to fairly satisfied & 74 & 92 & \\
\hline fairly to very dissatisfied & 26 & 8 & $P<0.001$ \\
\hline \multicolumn{4}{|l|}{ Future needs: } \\
\hline 'I am in need of psychological treatment in the future' & 46 & 15 & $P<0.001$ \\
\hline
\end{tabular}

n.s. $=$ no significant difference

characteristics and symptoms (body parts affected by polio, mobility devices used, new weakness, new pains, general fatigue, sleep disturbances, nightmares, problems with concentration, use of medication and other diseases) were entered stepwise in step 3 and psychosocial status (number of friends, loneliness, lack of support from parents and children and quality of life) were entered in step 4. Younger age of onset of polio (-0.16), and lack of support (0.15) weighted most in the equation, but only $17 \%$ of the variance was explained.

\section{Discussion}

The aim of the present study was to examine the relationship between early polio experiences and later psychological well-being. We stated the hypothesis that duration of hospitalization and lack of perceived support at the onset of polio influence upon the notion of being harmed by the early treatment. The hypothesis was confirmed. Further, the H-group stated that they currently suffer more from tiredness, pain, sleep disturbance, concentration problems, anxiety and 
Table 5 Current general social support and polio-related support. Responders confirming statement as 'true to a great extent' or 'true to a certain extent' are included in the questions on polio-related support. Values are given in percentage of the population

\begin{tabular}{|c|c|c|c|}
\hline Variable & $\begin{array}{l}\text { Harmed group } \\
(\mathrm{n}=391) \%\end{array}$ & $\begin{array}{l}\text { Non-harmed group } \\
\quad(\mathrm{n}=1053) \%\end{array}$ & $\begin{array}{c}\text { Chi-square/ } \\
\text { t-test }\end{array}$ \\
\hline \multicolumn{4}{|l|}{ General social support: } \\
\hline Two or more close friends & 81 & 89 & $P<0.001$ \\
\hline 'Does it occur that you feel lonely' sometimes/often & 75 & 50 & $P<0.001$ \\
\hline \multicolumn{4}{|l|}{ Polio-related social support: } \\
\hline 'I have often spoken to parents and siblings about polio' & 50 & 63 & $P<0.001$ \\
\hline 'I have spoken openly about polio with my friends' & 76 & 82 & n.s. \\
\hline 'I experience lack of polio-related understanding from spouse' & 44 & 20 & $P<0.001$ \\
\hline 'I experience lack of polio-related understanding from children' & 41 & 20 & $P<0.001$ \\
\hline
\end{tabular}

n.s. $=$ no significant difference

Table 6 Multiple stepwise linear regression analysis. Final analysis: Psychologically harmed by early treatment

\begin{tabular}{llcc}
\hline Step & Variable & Beta & Significance \\
\hline 1. Demographic data & age polio infection & -0.16 & -0.08 \\
& employment & 0.05 & n.s. \\
2. Data from polio onset & visit & 0.05 & n.s. \\
& care & 0.09 & n.s. \\
3. Current health status & mobility devices & -0.08 & n.s. \\
& new pains & -0.08 & n.s. \\
& concentration problems & -0.08 & 0.11 \\
4. Current psychosocial status & sedatives & 0.15 & $P<0.01$ \\
& lonely & 0.14 & $P<0.001$ \\
\hline
\end{tabular}

The following model was constructed: First, respondents' demographic characteristics were entered in a stepwise procedure in step 1, i.e. only variables resulting in a significant increase in the multiple correlation with group membership (H or $\mathrm{NH}$ ) were selected. Secondly, data about the onset of polio were entered in the same stepwise manner. Thirdly, current physical characteristics and symptoms were entered stepwise in step 3. Fourthly, psychosocial variables were entered in step 4. All variables are significant at the $P<0.001$ level stepwise. $\mathrm{R}^{2}=0.18$ Adjusted $\mathrm{R}^{2}=0.17 \mathrm{~F}(11,570)=11.66, P<0.001$

depression, and they use more medication such as analgesics and sedatives. In addition, they feel more lonely, report less social support and are more seldom employed than the NH-group. A causal relationship between early treatment and later problems can not be determined by this analysis.

When dichotomising into two groups, we relied on the respondent's answer to the question: 'I think I have been psychologically harmed by the treatment I received at the time I contracted polio'. It is our experience as psychologist and polio survivors, that most polio survivors have reflected on the impact of the early treatment on later well-being. The answer to the question is, however, based upon retrospective considerations and the perception of earlier events will be coloured by various experiences over the life-time. Thus, the reasons for answering 'yes' to the question may vary considerably. We will outline some possible explanations as to why some of the respondents feel more harmed than the others. The explanations are not mutually exclusive.

\section{Research on resilience}

Research on resilience in children and adolescence, i.e. why persons 'beat the odds' while others succumb to even modest distress, recognizes that the relation between a stressor and an outcome depends on many factors including the individuals' previous experiences, perception of events, coping skills, and social support. Each of these factors varies meaningfully with developmental stage, social background and cultural context. ${ }^{31}$ In our study, this complexity is illustrated by the fact that so many of the respondents in the $\mathrm{NH}$ group also have been exposed to stressors like contracting polio, hospitalization and separation from caregivers, without apparently being psychologically harmed by it. We therefore performed an additional 
statistical analysis. As dependent variable this time we choose whether the respondents had been hospitalized or not hospitalized at all during early onset of polio. No significant differences were found between the two groups on any symptom variables assessing current psychological distress. Again, this underlines the complexity between the role of stressors and other mediating factors.

\section{Effect of psychological traumas}

A relatively high proportion of the $\mathrm{H}$-group reported nightmares $(22 \%$ versus $7 \%$ in the NH-group), a symptom which is often looked upon as a long term effect of psychological trauma. In her definition of type II traumas, i.e. traumas following from long-standing or repetitive exposure to extreme external events, Terr includes stress due to prolonged hospitalization and pain. $^{32}$ Literature on post traumatic stress disorders (PTSD) has not, however, focused on childhood disabilities and hospitalization. ${ }^{33}$ Breslau et al. have studied the effects of traumatic experiences on depression. ${ }^{34}$ They found that among those exposed to a perceived traumatic event early in life, who beforehand were vulnerable to anxiety and depression, the incidence of depression was four times higher. Among polio survivors we would also expect that old and new strain cause cumulative effects on the psyche which may lead to depression.

\section{Effect due to severity of disability}

According to Grafman, no correlation has been found between severity of disability and psychological distress. $^{25}$ The Harmed-group was slightly more affected by polio in the acute phase. No differences in current body parts affected by polio or reported new weakness in polio-affected muscles were found between the groups, but a larger proportion of the H-group used mobility devices.

\section{The effect of coping skills}

Kuehn and Winters found a negative correlation between coping skills and quantity and severity of symptom distress. ${ }^{23}$ Our study contained no formal assessment of coping skills. However, it is likely that the NH-group had more effective coping skills in handling the new situation, and significantly more members of the $\mathrm{NH}$-group than the $\mathrm{H}$-group felt that they coped well with the late effects of polio. More important, the NH-members report significantly more support, which may facilitate coping. ${ }^{35}$

\section{The effect of employment}

In the Danish survey there was a significant correlation between employment and psychological well-being. ${ }^{29}$ In our study, more members on the H-group were unemployed.

\section{The effect of depression}

Tate et al. found that distressed/depressed subjects reported increased pain, rated their health as poorer and were less satisfied with life. ${ }^{22}$ The Harmed-group resembles Tate's Depressed Group. In the study by Kemp et al. post polio syndrome had some relation to depression, but family functioning and attitude towards disability were more important. ${ }^{24}$ Though the exact criteria of the post polio syndrome are not used in this study, the H-group also report of lack of support from family.

Kemp et al. $^{24}$ warn against overinterpreting intercorrelations of psychosocial variables with symptoms of depression, stating that a depressed person will see his or her family's functioning as worse than will a nondepressed person, even if it is the same. This warning is a proper one. On the other hand, longstanding or chronic depression may lead to family problems.

Kemp et al. ${ }^{24}$ found it to be of special concern that treatment of any kind for people with probable depressive disorders seemed nonexistent. This study serves as a reminder that polio survivors might need careful medical and psychological evaluation to diagnose their different symptoms. In our study, a large proportion of the Harmed-group claim that they will need professional psychological help in the future. Our study does not give simple answers as to why so many in the Harmed-group felt distressed. However, the results strongly underline the importance of having the psychosocial needs of polio survivors in mind.

\section{Conclusion}

The clinical implication from the study is that the emotional needs of polio survivors should be taken seriously in the rehabilitation setting of today. A psychologist should be part of the interdisciplinary team, and refer to psychiatric treatment when needed. For some polio survivors, family intervention is most needed, and peer support is valuable. But the study also has implications for how we should care for any ill or disabled children at the time of the original illness or injury. Early psychological evaluation, early treatment of emotional problems, and allowance for parental support are the key guidelines. Finally, it must be recognized that children may express distress and grief in ways different from adults.

\section{Acknowledgements}

We thank the polio survivors in this study for their participation, Kjetil Sundet, $\mathrm{PhD}$ for statistical advice and Mary Westbrook PhD and Johan K Stanghelle MD, PhD for comments.

\section{References}

1 Halstead LS, Wiechers DO. (Eds). Research and clinical aspects of the late effects of poliomyelitis. Birth Defects 1987; 23: $145-$ 155 . 
2 Halstead LS. Assessment and differential diagnosis for post-polio syndrome. Orthopedics 1991; 14: 1209-1217.

3 Halstead LS, Grimby G. (Eds). Post-polio syndrome. HanleyBelfuss, Philadelphia, 1995.

4 Westbrook MT, McIlwain D. Living with the late effects of disability: A five year follow-up survey of coping among postpolio survivors. Australian Occupational Therapy Journal 1996; 43: $60-71$.

5 Schanke AK. Psychological distress, social support and coping behavior among polio survivors: A 5-year perspective on 63 polio patients. Disability and Rehabil 1997; 19: 108-116.

6 Griffin JDM, Hawke WA, Barraclough WW. Mental hygiene in an orthopedic hospital. J Pediatr 1938; 13: $75-85$.

7 Barraclough WW. Mental reactions of normal children to physical illness. Am J Psychiatr 1937; 93: 865-877.

8 Fairchild LM. Some psychological factors observed in poliomyelitis patients. Am J Phys Med 1952; 31: 275-281.

9 Davis F. Passage through crisis: Polio victims and their families. Bobbs-Merrill, Indianapolis, 1963.

10 Robinson HA, Finesinger JE, Bierman JS. Psychiatric considerations in the adjustment of patients with poliomyelitis. $N$ Engl $J$ Med 1956; 254: $975-980$.

11 Schafer R. Psychoanalytic interpretation in the Rorschach testing. Grune \& Stratton, New York, 1954.

12 Meyer E. Psychological considerations in a group of children with poliomyelitis. J Pediatr 1947; 31: $34-48$.

13 Copellman FS. Follow-up of one hundred children with poliomyelitis. The Family 1944; 25: $289-297$.

14 Bruno RL, Frick NM. Stress and 'Type A' behaviour as precipitants of post-polio sequelae: the Felician/Columbian survey. (Eds). Halstead LS, Wiechers DO. Research and clinical aspects of the late effects of poliomyelitis. Birth defects 1987; 23: $145-155$.

15 Bruno RL, Frick NM. The psychology of polio as prelude to post-polio sequelae: Behavior modification and psychotherapy. Orthopedics 1991; 14: $1185-1193$.

16 Watts MJ. Post-polio syndrome: The role of type A behavior in psychosocial adaptation. Diss Abstr Int 1991; 52: 2789-2790.

17 Andersson S, Hofft E. Arousal, psychophysiological activity and fatigue in polio survivors. Abstr Eur J Neurol 1996; 3: 76.

18 Berlly MH, Strausser WW, Hall KM. Fatigue in postpolio syndrome. Arch Phys Med Rehabil 1991; 72: 115-118.

19 Conrady LJ et al. Psychological characteristics of polio survivors: a preliminary report. Arch Phys Med Rehabil 1989; 70: $458-463$.
20 Freidenberg DL et al. Postpoliomyelitis syndrome: Assessment of behavioral features. Neuropsych Neuropsychol Behav Neurol 1989; 2: $272-281$.

21 Clark K, Dinsmore S, Grafman J, Dalakas MC. A personality profile of patients diagnosed with post-polio syndrome. Neurol 1994; 44: $1809-1811$.

22 Tate DG et al. Prevalence and associated features of depression and psychological distress in polio survivors. Arch Phys Med Rehabil 1993; 74: $1056-1060$.

23 Kuehn AF, Winters RKV. A study of symptom distress, health locus of control and coping resources of aging polio survivors. $J$ Nurs Scholarship 1994; 26: 325-331.

24 Kemp BJ, Adams BM, Campbell ML. Depression and life satisfaction in aging polio survivors versus age-matched controls: Relation to postpolio syndrome, family functioning, and attitude toward disability. Arch Phys Med Rehabil 1997; 78: 187-192.

25 Grafman et al. Neuropsychology of Post-Polio Syndrome. Ann NY Acad Sci 1995; 753: $103-110$.

26 Lobben B, Øyhaugen S. The Polio Study 1994. Polio Special Issue 1995.

27 Halstead LS, Rossi CD. New problems in old polio patients: Results of survey of 539 polio survivors. Orthopedics 1985; 8: $845-850$.

28 Diard C, Ravaud JF, Held JP. French survey of postpolio sequelae. Risk factors study and medical social outcome. Am J Phys Med Rehabil 1994; 73: $264-267$.

29 Lønnberg F. Late onset polio sequelae in Denmark. J Scand Rehabil Med 1993; (suppl. 8).

30 Lande Wekre L, Stanghelle JK, Lobben B, Øyhaugen S. The Norwegian Polio Study 1994: A nationwide survey of problems in long-standing poliomyelitis. Spinal Cord 1998; 36: 280-284.

31 Haggerty RT, Sherrod LR, Garmezy N. (Eds). Stress, risk, and resilience in children and adolescents. Cambridge University Press, Cambridge, 1996.

32 Terr LC. Childhood traumas: An outline and overview. Am J Psychiatr 1991; 1: 10-20.

33 Van der Kolk BA, McFarlane AC, Weisæth L. (Eds). Traumatic Stress. Guilford Press, New York, 1996.

34 Breslau N, Davis GC, Peterson EL, Schultz N. Psychiatric sequelae of posttraumatic stress disorder in women. Arch Gen Psychiatr 1997; 54: $81-87$.

35 Taylor S. Health Psychology 3rd edn. McGraw-Hill, New York, 1995. 